\title{
Dominance rank of adult females and mating competition in Sichuan snub-nosed monkeys (Rhinopithecus roxellana) in the Qinling Mountains, China
}

\author{
HE HaiXia $^{1 \dagger}$, ZHAO HaiTao ${ }^{1,2 \dagger}$, QI XiaoGuang ${ }^{1}$, WANG XiaoWei ${ }^{2}$, GUO SongTao ${ }^{1}$, \\ JI WeiHong ${ }^{2,3}$, WANG ChengLiang ${ }^{2}$, WEI Wei ${ }^{1} \&$ LI BaoGuo ${ }^{1,2^{*}}$ \\ ${ }^{1}$ College of Life Sciences, Northwest University, Xi'an 710069, China; \\ ${ }^{2}$ Institute of Zoology, Shaanxi Academy of Sciences, Xi'an 710032, China; \\ ${ }^{3}$ Institute of Natural Resources, Massey University, Albany, Auckland 1311, New Zealand
}

Received March 17, 2012; accepted June 21, 2012; published online January 14, 2013

\begin{abstract}
Dominance hierarchy reflects resource competition in male primates as well as females. In this study, we collected data on the social rank and mating competition of female Sichuan snub-nosed monkeys from September 2009 to June 2010 in the Qinling Mountains, Shaanxi, China. Displacement was used to determine social hierarchy of the studied wild females. A total of 1223 displacement bouts between adult females and 316 mating behaviors within one-male units (OMUs) were recorded. Competitive displacement among females was very low ( 0.22 displacements per observation hour). The dominant ranks of females in target OMUs were determined by displacement, from one OMU to another: JB unit: YL > DBC > YCM >XBC > BD; JZT unit: XHW > JG > DT; PK unit: QQ > TM > HF; LP unit: SK > TH > WM. Higher-ranking females performed significantly more sexual behavior than lower-ranking females in this rare monkey. High-ranking females were more likely to win mating contests within those OMUs. Based on these studies, we assessed the social relationships among adult females and clarified possible explanations for the strategies of female mating competition in the OMUs. Furthermore, the notion that reproductive success may also be related to female dominance hierarchies in this polygynous species should be considered in future research.
\end{abstract}

Sichuan snub-nosed monkeys (Rhinopithecus roxellana), female dominance rank, displacement behavior, mating competition, reproduction

Citation: He H X, Zhao H T, Qi X G, et al. Dominance rank of adult females and mating competition in Sichuan snub-nosed monkeys (Rhinopithecus roxellana) in the Qinling Mountains, China. Chin Sci Bull, 2013, 58: 2205-2211, doi: 10.1007/s11434-012-5649-2

Dominance status plays a fundamental role in social interactions of individuals in group-living primates $[1,2]$. Dominance rank is defined as the ability of one individual to consistently evoke submissive behavior in all individuals within the same unit. Such social relationships are useful to describe social organizations [3] and to estimate an individual's priority access to resources [4]. Currently, dominance rank is regarded as a self-regulatory mechanism to reduce competition, and to sustain social affinity and organization stability because all individuals know their own social status

$\dagger$ These authors contributed equally to this work.

*Corresponding author (email: baoguoli@nwu.edu.cn) in the given social network [5].

Competition among males, which is usually intense in most nonhuman primates because of their physical features and social roles, was widely concerned. Social dominance rank in males is easily detected and conspicuous, but that of females may be obscure and weak because females are generally more tolerant and responsive with one another than are males [6]. Walters and Seyfarth [6] considered the dominance rank in females to be weak, especially in tolerant primate species. Reproductive skew theories state that dominance rank influences adult females' resource acquisition [7]. Wherein, mating opportunity is an important predictor for measuring female benefits, which is ultimately 
influenced by female dominance rank. Dominance rank can be reflected as frequencies and intensities of social activities, including food competition and mating opportunities among different females [7]. In addition, dominant individuals influence the mating opportunities of subordinates, and have higher reproductive fitness in species that form hierarchical family groups [7], indicating that dominant individuals may spend more time mating with their own breeding males than do subordinates [8-11]. In spite of this, the highest-ranking individuals do not monopolize all desired resources and mating opportunities still exist for subordinates in the majority of primate species [8-11].

The pattern of female dominance hierarchy varies in primate species with different social structure. For example, in despotic species high-ranking females always monopolize desired resources and dominance rank among females is obvious, whereas female rank is much weaker in leafmonkeys which are tolerant species and not despotic. Following the evolution of social systems, female dominance hierarchy is more complex than male dominance hierarchy in relation to function and mechanism. Multi-level societies, where social relationships among individuals are organized into two or more levels within the community, are the most complex and complete social structure, wherein one-male units (OMU) are the basic social and reproductive unit [12]. This multi-level society has only been observed in gelada and hamadryas baboons and snub-nosed monkeys [12]. According to research on aggressive behavior in matrilineal society gelada baboons, female dominance ranks exist, with the highest-ranking female gaining more mating opportunities than the lowest-ranking female [13] because females do not migrate among OMUs and often form female-bonds within OMUs. Conversely, female ranks do not exist and mating opportunities are more equally distributed among adult females within hamadryas OMUs because females migrate among OMUs and maintain a particular, intimate relationship with the leader male [12-14]. To date, however, no such research has been conducted on Sichuan snubnosed monkeys [12].

Sichuan snub-nosed monkeys exhibit a multi-level social stratum that varies over time, although female migration between OMUs occurs less often in Sichuan snub-nosed monkeys than in hamadryas. A troop includes all-male units (AMUs) and several OMUs, which consist of one breeding male, multiple females, and their offspring. Conflicts among different individuals within OMUs do occur, including aggressive and submissive behavior [15]. Aggressive behaviors of adult females include biting, fighting, chasing, threatening, and displacing when experiencing scramble competition [16]. Displacement occurs when a high-ranking individual approaches and a low-ranking individual moves away. In Sichuan snub-nosed monkeys, dominance rank in males is determined by aggression and aggressive behaviors. For females, however, this method might not be particularly effective [16]. Because females are generally regarded as less aggressive and more tolerant, in this study we hypothesized that female social rank could be determined by displacement rather than aggression, this displacement has been successfully applied in many other primate species [17-19].

Based on the social structure and relationship characteristics of the Sichuan snub-nosed monkeys, we made the following preliminary predictions regarding female dominance rank and female mating competition within the OMUs. Firstly, females will have few interactions in the female-migration group, thus further reducing the frequency of female displacement [12]. We predicted that the frequency of displacement among females would be relatively low in Sichuan snub-nosed monkeys. Secondly, displacement behavior between females under natural conditions exists and is useful to delineate the female dominance hierarchies $[20,21]$. Thus we predicted that dominance hierarchies among females could be determined using only displacement behavior in free-ranging Sichuan snub-nosed monkeys. Thirdly, the dominance ranks among females within OMUs are propitious to maintain group cohesion and energy requirements. Furthermore, it was presumed that high-ranking individuals possess greater reproductive potential and that high-ranking females should be more attractive as mating partners than other females within the OMU, affecting the mating strategies of others [22-24]. Thus we predicted that high-ranking females gained more mating benefits than low-ranking females within the OMUs of this polygynous species.

In this study, we aimed (1) to examine the presence of dominance ranks among adult females by displacement; (2) to examine the power of female dominance rank in mating competition; and (3) to discuss possible strategies of female mating competition in OMUs in Sichuan snub-nosed monkeys.

\section{Materials and methods}

\subsection{Study area and animals}

This study was conducted near Yuhuangmiao village $\left(108^{\circ} 14^{\prime}-108^{\circ} 14^{\prime} \mathrm{E}, 33^{\circ} 45^{\prime}-33^{\circ} 50^{\prime} \mathrm{N}\right)$ in Zhouzhi National Nature Reserve on the northern slopes of the Qinling Mountains in Shaanxi Province, China [25]. The altitude of the study site is $1400-2890 \mathrm{~m}$ above sea level. The vegetation varies with altitude from coniferous forests above 2600 $\mathrm{m}$ to mixed coniferous broadleaf forests above $2200 \mathrm{~m}$ and deciduous broadleaf forests at low elevations [25]. Two groups of Sichuan snub-nosed monkeys, the West Ridge Group and the East Ridge Group, inhabit this area and they are separated by the Nancha River [25].

We studied the behavior of adult females in four OMUs of the West Ridge Group. The group consisted of fourteen adult females, four adult males, and seven infants (Table 1). Based on physical characteristics such as facial features and 
Table 1 Basic information of four target units ${ }^{\text {a) }}$

\begin{tabular}{|c|c|c|c|c|}
\hline Resident-male & LP & JB & PK & JZT \\
\hline Adult female & WM, SK, TH & YL, YZM, BD, DBC, XBC & HF, TM, QQ & JG, XHW, DT \\
\hline Sub-adult & $\mathrm{XH}, \mathrm{XB}, \mathrm{XD}, \mathrm{XF}, \mathrm{XM}, \mathrm{XW}, \mathrm{GG}$ & $\mathrm{NY}, \mathrm{X}_{1} \mathrm{Y}_{1}, \mathrm{XK}, \mathrm{XY}, \mathrm{GY}, \mathrm{GXC}$ & GF, GS, J3.5 years, J2.0 years & J3.5 years, J3.5 years, J3.5 years \\
\hline Juvenile & $\mathrm{Y}_{1} \mathrm{M}_{1}, \mathrm{YH}, \mathrm{YW}, \mathrm{o}^{\star}$ & YD, YDC, YM & YQ, YT & \\
\hline Infant & & $\mathrm{H}_{1} \mathrm{Y}_{1}, \mathrm{HYM}, \mathrm{HDC}, \mathrm{HY}$ & $\mathrm{H}_{1} \mathrm{~F}_{1}$ & $\mathrm{HG}, \mathrm{HD}$ \\
\hline Total & 14 & 19 & 11 & 9 \\
\hline
\end{tabular}

a) The unit is named after its resident male.

body size, all the individuals were identified.

\subsection{Food provisioning}

Provisioning was conducted in a $15 \mathrm{~m} \times 30 \mathrm{~m}$ area at Sanchakou (1646 m above sea level) in Gongnigou valley within the home range of the West Ridge group. Every morning for $113 \mathrm{~d}$, the monkeys were located and herded to the provisioning site. We began our observations at about 10:00 am. Provisioned food consisted of corn, radishes, and apples. Food was provided three times a day at 10:00 am, 12:00 am, and 2:00 pm. On average, $200 \mathrm{~g}$ of food were provided per monkey per day, which is a minor proportion of their daily food consumption [26,27]. The distances between the monkeys and the observers were shortened between 0.5 and $50 \mathrm{~m}$ and we could recognize the identities of focal females easily when they were feeding. Following provisioning, the monkeys would freely leave the provisioning site $[28,29]$.

\subsection{Data collection}

The troop was observed for six hours per day from September 2009 to June 2010. Focal observations with continuous recording were conducted to avoid oversight of relevant behaviors. Displacement is defined as one individual leaving at the approach of another individual within $1 \mathrm{~m}$, including supplanting and avoidance [30]. All adult females within each target unit were focal animals for one day from 10: 00 am to 4: $00 \mathrm{pm}$ and the observation times were equal among focal units. The data on displacement and mating behavior were recorded. Female dominance hierarchies were constructed based on displacement behaviors [31].

\subsection{Data analysis}

Displacement data of adult females within OMUs were calculated as the ratio of displacement $=$ number of displacement by actor/total of (displacement by actor and by partner) within OMUs, and were entered into matrices with "winners" plotted along columns and "losers" plotted along rows to determine dominance ranks [32].

In addition, the nonparametric Spearman Rank Correlation test was used to test for correlation between female ranks and mating frequencies.

\section{Results}

\subsection{Adult female rank}

During the 113-d study period, no females dispersed among different OMUs. A total of 1415 displacement bouts were recorded, with 1223 displacements occurring between adult females within OMUs. The additional 192 displacements occurred among different OMUs and were excluded in the data analysis. Of 1223 displacements, 416 occurred in the JB unit, 210 occurred in the JZT unit, 345 occurred in the PK unit, and 252 occurred in the LP unit.

Displacement behavior among female Sichuan snubnosed monkeys occurred at a rate of 0.22 interactions per hour per unit. Rank orders among females were determined from one OMU to another (Table 2): JB unit: $\mathrm{YL}>\mathrm{DBC}>$ YCM >XBC > BD; JZT unit: XHW > JG > DT; PK unit: QQ > TM > HF; LP unit: SK > TH > WM. Furthermore, the highest-ranking individuals did not attack only the lowestranking females. For example, displacement between YL and BD $(n=28)$ was not higher than that between YL and $\mathrm{XBC}(n=56)$ in Table 2.

\subsection{Female rank and mating competition}

During the study period, 316 mating events were observed, with 104 recorded in the JB unit (0.15 interactions per hour), 72 in the JZT unit (0.11 interactions per hour), 65 in the PK unit (0.10 interactions per hour), and 75 in the LP unit ( 0.11 interactions per hour) (Table 2). There was a positive correlation between frequencies of mating (the 14 females in target units during the study period) and female ranks (with different ranks ranging from the highest rank, 1, to lowest rank, 5) $\left(-1<r_{s}=-0.879<0 ; P_{\mathrm{JB}, \mathrm{JZT}, \mathrm{LP}, \mathrm{PK}}<0.05\right)$, indicating higher-ranking females mated more than lower- ranking females $(P<0.05)$ (Table 3, Figure 1).

\section{Discussion}

Dominance rank among adult females of Sichuan snubnosed monkeys (Rhinopithecus roxellana) was positively correlated with mating competition as is often observed in other leaf monkey species [33]. The frequency of displacement behavior among adult females within the OMUs was low, indicating that $R$. roxellana females exhibited affinitive 


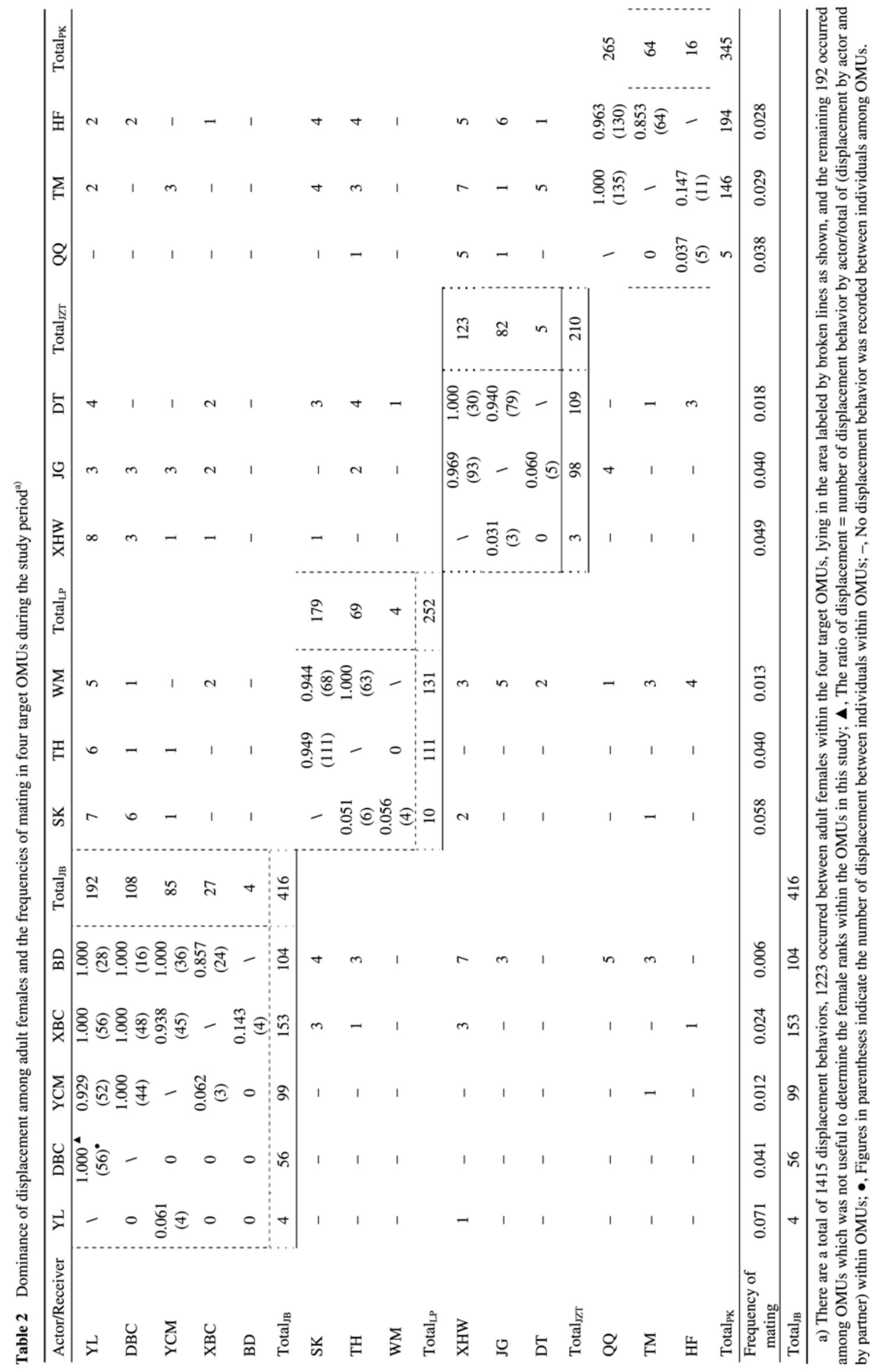


Table $3 \quad P$ and correlation coefficient $\left(r_{s}\right)$ values between female rank and mating behavior in target units

\begin{tabular}{lrrrr}
\hline & JB unit & JZT unit & PK unit & LP unit \\
\hline Correlation coefficient $\left(r_{s}\right)$ & -0.900 & -1.000 & -1.000 & -1.000 \\
Value of $P$ & 0.037 & 0.000 & 0.000 & 0.000 \\
\hline
\end{tabular}

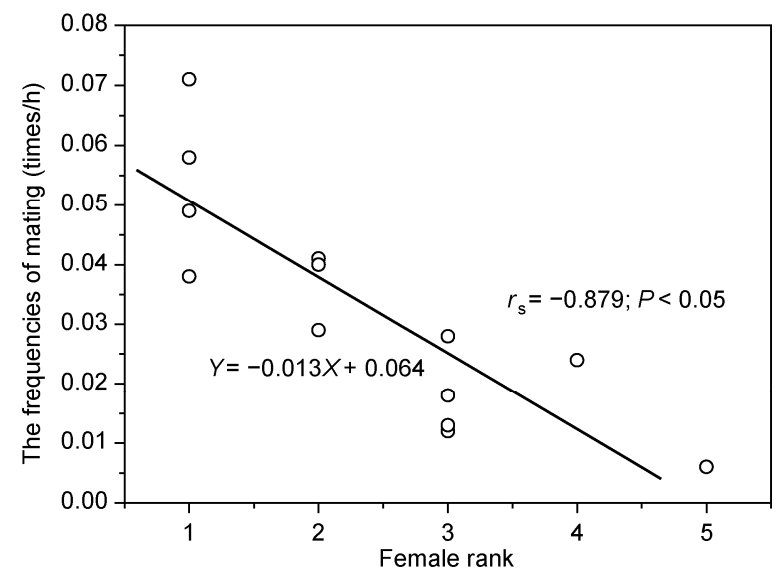

Figure 1 Positive correlation between the frequency of mating and female rank (ranks ranged from highest rank, 1, to lowest rank, 5): the high-rank- ing females had higher mating frequencies than the low-ranking females within OMUs.

behavior. However, high-ranking females still mated more often than low-ranking females in this polygynous species.

Like other leaf monkey species [29], the $R$. roxellana adult females in our study group rarely fought physically, stopping at threatening (e.g. displacement) and vocal warnings $[34,35]$. Compared with interaction rates of the Thomas langurs (Presbytis thomasi; 1.20 interactions per unit per observation hour [33]) and black-and-white colobus monkeys (Colobus polykomos; 0.70 interactions per unit per observation hour [36]), the aggressive rate of the Sichuan snub-nosed monkey was rather low. Previous research has determined that dominance hierarchy is "indulgent" for dominant individuals and "relaxed" for subordinate individuals in captive Sichuan snub-nosed monkeys [37]. A low rate of agonistic interactions may coincide with weak or indiscernible dominance hierarchies [38,39], but female dominance hierarchy in $R$. roxellana did exist. Similar observations have been made in other primate species, e.g. chimpanzees in Gombe [40] and in Mahale [41,42].

Although dominance rank was not confirmed as the determinant factor of social relationships in our study, it certainly plays an important role in the social lives of female Sichuan snub-nosed monkeys. The difference in female rank likely represented differences in the quality of the social relationships. The mating data were, to some extent, more easily influenced by the presence of female rank. However, female ranks may be affected by more than two factors, which could not necessarily be exclusive. Firstly, it is possible that these female ranks were influenced by kin- ship, whereby a dominance hierarchy matrix was observed where some younger females possessed a higher rank. For example, DBC in JB unit was the offspring of YL and was younger than $\mathrm{XBC}$, but had a higher rank than the latter. Secondly, the dominance rankings may be related to the age of female. It is generally believed that older females have more experience than younger females, with the former having priority to dominant resources. Unfortunately, due to a lack of systematic data on these focal females, we were unable to address these kinship-related and age-related issues. Additionally, because female rank is a complex phenomenon with many relative factors remaining unclear, further long-term studies are required to elucidate the various characteristics of female rank.

The presence of female ranks is beneficial perhaps for group stability and can predict mating benefit in polygynous primates [43]. High-ranking females are generally more attractive, leading to the greater frequency of social interactions and mating opportunities between adult females and breeding males [43]. High-ranking $R$. roxellana females exhibited greater mating frequencies than did the lowranking females, which suggests high-ranking females were more attractive to the breeding male. Although reproductive skew theory was initially defined for insects and birds [7,11], the concept of dominance based on aggression in mammalian social structures $[20,21,44]$ has been highlighted in many primate species recently [45]. In this study, the relational result on social behavior in the Sichuan snubnosed monkey group was consistent with that observed in gelada baboons [13] and the predictions of the reproductive skew theory. According to the dominance relationship of females, it can be deduced that dominant females might gain more mating opportunities than subordinates. More importantly is the fact that high-ranking females may affect the mating strategies of lower-ranking females within OMUs.

Because female Sichuan snub-nosed monkeys within OMUs were relatively non-aggressive and displayed friendly contact with each other, they could share advantageous resources (i.e. mating opportunity) with other individuals under natural conditions. Such results are similar with our previous findings that antagonistic levels among adult females within OMUs are low and that the Sichuan monkey is a tolerant species [16]. This may explain why subordinates disperse into other OMUs for mating opportunities when competitive suppression of advantageous resources is intense. Unlike other colobine monkeys, freeranging Sichuan snub-nosed monkey females mate with males throughout the year (even during the birthing season) and the birthing time of new offspring shows diversity under our observation in wild. Accordingly, we preliminarily concluded that the frequency of mating was a possible indicator of reproductive success, and reproductive success was likely related to female rank. However, because reproductive success is limited by many factors [46], further studies 
on this species are required to clarify the relationship among female rank, mating, and reproductive success.

In conclusion, our results support our hypotheses. Firstly, among the study group of Sichuan snub-nosed monkeys, female dominance rank was observed to be weak. Secondly, the positive correlation between female rank and mating competition might reflect male mating preference. Thirdly, higher-ranking females were more likely to be a recipient in a mating relationship than lower-ranking females were, influencing the mating strategies of the latter within the OMUs.

This work was supported by the Key Program of National Natural Science Foundation of China (31130061), National Natural Science Foundation of China (30970444, 30970168, 30970379), Special Foundation of Shaanxi Academy of Sciences, China (2010K-01), Western Light Talent Culture Project (2011DF05), Research Fund for the Doctoral Program of Higher Education of China (20106101110005), Natural Science Foundation of Shaanxi Province China (2010JM3006) and Cosmo Oil Eco Card Fund of Japan (2005-2012). We thank Zhouzhi National Nature Reserve for their cooperation and permission to conduct this study. We also thank the local farmers for support and assistant; Dapeng Zhao, Jian Zhang, Kang Huang, Bin Yang, Weiwei $F u$, Dong Zhang, Linlin Wu, and Hongyang Zhang for assistance with our field observations.

1 Maslow A H. The role of dominance in the social and sexual behavior of infrahuman primates. J Genet Psychol, 1934, 48: 261-277

2 Zuckerman S. The Social Life of Monkeys and Apes. New York: Harcourt Brace \& Co, 1932

3 Pereira M E, Kaufman R, Kappeler P M, et al. Female dominance does not characterize all of the Lemuridae. Folia Primatol, 1990, 55: 96-103

4 Wilson E O. Sociobiology: The New Synthesis. Cambridge, Massachusetts: Harvard University Press, 1975

5 de Waal F B M. Dominance 'style' and primate social organisation. In: Staden V, Foley R A, eds. Comparative Socioecology. Oxford: Blackwell, 1989. 243-263

6 Walters J R, Seyfarth R M. Conflict and cooperation. In: Smuts B B, Cheney D L, Seyfarth R M, et al., eds. Primate Societies. Chicago, IL: University of Chicago Press, 1987. 306-317

7 Emlen S T. The evolution of helping. I. An ecological constraints model. Am Nat, 1982, 119: 29-39

8 Emlen S T. The evolution of helping. II. The role of behavioral conflict. Am Nat, 1982, 119: 40-53

9 Emlen S T. Benefits, constraints and the evolution of the family. Trends Ecol Evol, 1994, 9: 282-285

10 Vehrencamp S L. A model for the evolution of 'despotic' versus 'egalitarian' species. Anim Behav, 1983, 31: 667-682

11 Reeve H K, Keller L. Partitioning of reproduction in mother-daughter versus sibling associations: A test of optimal skew theory. Am Nat, 1995, 145: 119-132

12 Qi X G, Zhang P, Li B G, et al. The diversity of polygynous system in multi-levei society of non-human primates (in Chinese). Acta Theriol Sin, 2010, 30: 322-338

13 Kawai M. Ecological and Sociological Studies of Gelada Baboons. Tokyo: Kodansha Limited, 1979

14 van Schaik C P. The ecology of social relationships amongst female primates. In: Standen V, Foley R A, eds. Comparative Socioecology. The Behavioral Ecology of Humans and Other Mammals. Oxford: Blackwell, 1989. 195-218

15 Zhang P, Watanabe K, Li B G. Female social dynamics in a provisioned free-ranging band of the Sichuan snub-nosed monkey (Rhino- pithecus roxellana) in the Qinling Mountains, China. Am J Primatol, 2008, 70: $1-10$

16 Li B G, Li H Q, Zhao D P, et al. Study on dominance hierarchy of the golden snub-nosed monkey (Rhinopithecus roxellana) in Qinling Mountains (in Chinese). Acta Theriol Sin, 2006, 26: 18-25

17 Bygott J D. Agonistic behavior, dominance and social structure in wild chimpanzees of the Gombe National Park. In: Hamburg D A, McCown E R, eds. The Great Apes, Menlo Park, CA: Benjamin/Cummings, 1979. 405-427

18 de Waal F B M. Exploitative and familiarity-dependent support strategies in a colony of semi-free living chimpanzees. Behaviour, 1978, 66: 268-311

19 Noe R, de Waal F B M, van Hooff J. Types of dominance in a chimpanzee colony. Folia Primatol, 1980, 34: 90-110

20 Bernstein I S. Dominance: The baby and the bathwater. Behav Brain Sci, 1981, 4: 419-457

21 Drews C. The concept and definition of dominance in animal behavior. Behaviour, 1993, 125: 283-313

22 Berenstain L, Wade T D. Intrasexual selection and male mating strategies in baboons and macaques. Int J Primatol, 1983, 4: 201-235

23 Robinson J G. Intrasexual competition and mate choice in primates. Am J Primatol, 1982, 1: 131-144

24 Shively C, Smith D G. Social status and reproductive success of male Macaca fascicularis. Am J Primatol, 1985, 9: 129-135

$25 \mathrm{Li} \mathrm{B} \mathrm{G}$, Chen C, Ji W H, et al. Seasonal home range changes of the golden snub-nosed monkey (Rhinopithecus roxellana) in Qinling Mountains of China. Folia Primatol, 2000, 71: 375-386

26 Qi J F. The feed and reproduction of the Sichuan snub-nosed monkeys. In: Chen F G, ed. Progress in the Study of Sichuan Snub-nosed Monkeys. Xi' an: Northwest University Press, 1989. 287-292

27 Li B G, Zhao D P. Copulation behavior within one-male groups of wild Rhinopithecus roxellana in the Qinling Mountains of China. Primates, 2007, 48: 190-196

28 Zhang P, Li B G, Wada K Z, et al. Social structure of a group of golden snub-nosed monkeys (Rhinopithecus roxellana) in the Qinling Mountains of China (in Chinese). Acta Zool Sin, 2003, 49: 727735

29 Qi X G, Li B G, Tan C L, et al. Spatial structure in a golden snubnosed monkey (Rhinopithecus roxellana) group in Qinling Mountains while being in no-locomotion (in Chinese). Acta Zool Sin, 2004, 50: 697-705

30 Zhang P, Watanabe K, Li B G, et al. Dominance relationship among one-male units in a provisioned free-ranging band of the Sichuan snub-nosed monkeys (Rhinopithecus roxellana) in the Qinling Mountains, China. Am J Primatol, 2008, 70: 634-641

31 de Vries $\mathrm{H}$. An improved test of linearity in dominance hierarchies containing unknown or tied relationships. Anim Behav, 1995, 50: 1375-1389

32 Rowell T E. The concept of social dominance. Behav Biol, 1974, 131-154

33 Sterck E H M, Steenbeek R. Female dominance relationships and food competition in the sympatric Thomas langur and Long-tailed macaque. Behaviour, 1997, 134: 749-774

34 Li B G, Zhang P, Watanabe K, et al. Does allogrooming serve a hygienic function in the Golden Snub-nosed Monkey (in Chinese). Acta Zool Sin, 2002, 48: 707-715

35 Zhang J, Zhao D P, Li B G. Postconflict behavior among female Rhinopithecus roxellana within one-male units in the Qinling Mountains, China. Curr Zool, 2010, 56: 222-226

36 Korstjens A H, Sterck E H M, Noe R. How adaptive or phylogenetically inert is primate social behavior? A test with two sympatric colobines. Behaviour, 2002, 139: 205-225

37 Ren R M, Qi H, Liang B, et al. The reconciliation behavior of golden monkeys Rhinopithecus roxellana in small breeding groups. Primates, 1991, 32: 321-327

38 Isbell L A, Young T P. Ecological models of female social relationships in primates: Similarities, disparities and some directions for future clarity. Behaviour, 2002, 139: 177-202

39 Koenig A. Competition for resources and its behavioral consequences 
among female primates. Int J Primatol, 2002, 23: 759-783

40 Goodall J. The chimpanzees of Gombe: Patterns of behavior. Cambridge, MA: Harvard University Press, 1986

41 Nishida T. The social structure of chimpanzees of the Mahale Mountains. In: Hamburg D A, McCown E R, eds. The Great Apes. Menlo Park, CA: Benjamin/Cummings, 1979. 73-122

42 Nishida T, Hosaka K. Coalition strategies among adult male chimpanzees of Mahale Mountains, Tanzania. In: McGrew W C, Marchant L F, Nishida T, eds. Great Ape Societies. Cambridge, UK: Cambridge University Press, 1996. 114-134
43 David F, Peter S. Dominance and the social behavior of adult female bonnet macaques (Macaca radiata). Primates, 1981, 22: 368-378

44 Hand J L. Resolution of social conflicts: Dominance, egalitarianism, spheres of dominance and game theory. Q Rev Biol, 1986, 61: 201220

45 Li B G, Zhao D P. Female multiple copulations among wild Sichuan snub-nosed monkeys (Rhinopithecus roxellana) in Qinling, China. Chin Sci Bull, 2005, 50: 942-944

46 Harcourt A H. Dominance and fertility among female primates. J Zool, 1987, 213: 471-487

Open Access This article is distributed under the terms of the Creative Commons Attribution License which permits any use, distribution, and reproduction in any medium, provided the original author(s) and source are credited. 